\title{
Notas acerca de la expulsión de los judíos en la diócesis de Osma (Soria)
}

\author{
EnRique Cantera Montenegro *
}

\begin{abstract}
RESUMEN
Como en las restantes comarcas hispanas, la promulgación del decreto de expulsión de 1492 dio lugar a actitudes diversas entre la población judía de las ciudades y villas del obispado de Osma. En tanto que un sector optó por la conversión al cristianismo, en buen número de casos más por interés que por una auténtica convicción, otro sector, probablemente mayoritario, se negó a abandonar su religión y costumbres ancestrales, por lo que hubo de salir del reino de Castilla, dirigiéndose en su mayor parte hacia Portugal. Pero fueron también bastantes los que algún tiempo después, y como consecuencia de las penalidades del exilio, retornaron a sus localidades de origen, tras recibir el bautismo en Portugal o en la misma frontera.
\end{abstract}

\section{ABSTRACT}

As in the rest of the spanish regions, the enactment of the expulsion decree of 1492 provoked different attitudes among the jewish population in cities and towns of the bishopric of Osma. While some of them chosed the conversion to Christianism - a big number of them did it more by interest than by authentic conviction-others, probably the majority of them, refused to abandon their religion and ancient traditions, so they were forced to leave the kingdom of Castilla, mainly to Portugal. But they were as well many who, sometime after, and as a consequence of the difficulties of the exile, returned to their original places, after being baptized in Portugal or in the border.

* UNED. 
1. Hace ya bastantes años me aproximé al estudio de las relaciones cristiano-judías en la diócesis de Osma en el último tercio del siglo XV ${ }^{1}$, en un trabajo en el que en uno de sus apartados procedí a analizar, brevemente, las consecuencias de la aplicación del decreto de expulsión general de 31 de marzo de 1492 en las comunidades judías de esta comarca ${ }^{2}$. Es éste un trabajo que, en su día, comentamos ampliamente el profesor Antonio Antelo y yo, en aquellos tiempos en los que nos sentábamos frente por frente en el único despacho de que entonces disponía el Departamento de Historia Medieval, en el primitivo -y entonces también único- edificio de la UNED; la penuria de espacio físico se veía compensada con la cálida y siempre extraordinariamente culta conversación de Antonio Antelo, de quien tanto aprendí.

En este merecido homenaje a su memoria, vuelvo sobre aquel antiguo tema, con la intención de tratar con mayor detalle acerca de la actitud de los judíos que residían en distintas localidades del obispado de Osma ante la promulgación del decreto expulsorio.

2. Como en las restantes comarcas de los reinos hispanos, no cabe ninguna duda de que un importante número de judíos de las tierras que constituyen el objeto de nuestro estudio se convirtió al cristianismo en 1492. Debido a que el bautismo les posibilitaba la permanencia en sus lugares habituales de residencia y la conservación de todas sus propiedades, muebles y raíces, es legítimo sospechar que buen número de conversiones respondieron más a un mero interés que a un auténtico convencimiento. Conscientes de esta realidad, los Reyes Católicos impulsaron una intensa campaña misional entre los judíos en el espacio temporal que medió entre la publicación del decreto de expulsión y su salida del reino, con el fin de lograr la conversión al cristianismo del mayor número posible; del mismo modo, se preocuparon más tarde por la instrucción religiosa de los nuevos conversos, conscientes de su desconocimiento prácticamente absoluto de la religión cristiana ${ }^{3}$. Por su parte, los cristianos viejos acogieron con sumo

\footnotetext{
1 El territorio de la diócesis de Osma era entonces más extenso que en la actualidad, pues si no comprendía las tierras situadas en el extremo suroriental de la actual provincia de Soria (tierras de Almazán y Medinaceli, principalmente), que quedaba englobado en la diócesis de Sigüenza, por el contrario abarcaba buena parte del sur de la actual provincia de Burgos (Aranda de Duero, Peñaranda de Duero, Gumiel de Mercado, Gumiel de Izán, Roa, Coruña del Conde), así como algunas ciudades y villas que hoy en día pertenecen a las diócesis de Segovia, Sigüenza y Logroño.

2 Enrique Cantera Montenegro, "Relaciones judeocristianas en la diócesis de Osma en el último tercio del siglo XV", en Encuentros en Sefarad. Ciudad Real. Instituto de Estudios Manchegos, 1987, pp. 103-135.

3 Véase sobre este particular el interesante estudio de María del Pilar RÁBADE OBRADÓ, «La instrucción cristiana de los conversos en la Castilla del siglo XV», en En la España Medieval, 22 (1999), pp. 367-393 (en concreto, pp. 386-392).
} 
escepticismo, suspicacia y reticencia la masiva conversión de judíos al cristianismo, lo que tenía una cierta justificación si tenemos en cuenta que las conversiones simuladas eran aceptadas por algunos rabíes judíos desde los tiempos de Maimónides, cuando él mismo había fingido una conversión al Islam en plena persecución almohade ${ }^{4}$.

Son hasta cierto punto frecuentes las referencias documentales a la conversión interesada de judíos vecinos de diversas localidades de la diócesis de Osma. Pese a que la mayor parte proceda de declaraciones de testigos en procesos inquisitoriales promovidos contra judeoconversos acusados de judaizar ${ }^{5}$, no creo que quepa dudar de la veracidad de las mismas. Es éste el caso de María Álvarez, difunta, vecina que había sido de Soria, quien, según la testificación hecha el día 15 de abril de 1491 ante el Tribunal de la Inquisición por doña Vellida, judía vecina de Soria y viuda de Mosé Françés, realizaba numerosas prácticas judaicas, y en varias ocasiones le había oído decir

«que mucho estava arrepentida porque se avía tornado christiana, e que nunca se tornara christiana syno por unas debdas que devía ella e su marido».

Doña Vellida habría sido testigo de este comportamiento de María Álvarez, por cuanto durante siete años habían tenido sus casas juntas, «con un postigo en medio de sus casas" ${ }^{6}$. Idéntica explicación de su conversión al cristianismo es la que ofrece Pero Núñez de Santa $\mathrm{Fe}$ «el Ronquillo» (de judío Yuçe de Valladolid), vecino de Coruña del Conde, quien, según la declaración de Juan de las Cámaras, vecino de Aranda de Duero, habría afirmado en una ocasión

"que sy no fuera por las debdas que le devían, que no se tornara christiano ni veniera de Portugal»?

En otra ocasión es fray Francisco de Aranda, franciscano natural de Aranda de Duero, quien habría oído decir a Pero Núñez de Santa Fe

\footnotetext{
4 Véase Fernando Diaz Esteban, «La expulsión y la justificación de la conversión simulada», en Sefarad, LVI-2 (1996), pp. 251-264.

5 Es particularmente interesante la documentación que acerca de la actuación del Tribunal del Santo Oficio en el obispado de Osma se conserva en el Archivo General de Simancas, Patronato Real, Inquisición, leg. 28/73, fols. 937r-1.121v, y que dio a conocer hace algún tiempo, en una excelente edición crítica, Carlos CarRete ParRondo, Fontes ludaeorum Regni Castellae. II. El Tribunal de la Inquisición en el Obispado de Soria (1486-1502). Salamanca. Universidad Pontificia de Salamanca-Universidad de Granada, 1985.
}

6 C. Carrete, op. cit., n. ${ }^{\circ} 111$, p. 59.

C. Carrete, op. cit., n. ${ }^{\circ} 231$, p. 107. 
"que no se avía tornado christiano salvo por venirlas a cobrar - se refiere a unas "obligaçiones", es decir a unos documentos por los que se reconoce alguna deuda-, y que para qué le avian rogado que se tornase christiano, quél no avía gana. Y que en otras palabras, de que no se acuerda, sygnificó que nin hera christiano ni lo avía gana de ser» ${ }^{8}$.

Pese a que con frecuencia hubieran actuado por conveniencia, el pesar y el arrepentimiento por el abandono de la religión y de las costumbres judías debió atormentar a muchos de los judeoconversos que habían abrazado el cristianismo en 1492. Así Alonso López, vecino de Villatuelda (Burgos) y zapatero de profesión, cosiendo un día unos zapatos en Terradillos de Esgueva (Burgos), en la casa de Alonso Tamayo, ante la afirmación de Juan Martínez de Abad de que existían sospechas de que no era buen cristiano porque no traía consigo a su mujer, que permanecía en Ciudad Rodrigo ${ }^{9}$, y de que era cristiano a la fuerza, le respondió:

«Juro a Dios que dezís la verdad, que buena Ley teníamos» ${ }^{10}$.

En parecidos términos se expresaría Juan de Buendía, cristiano nuevo vecino de Momblona (Soria), de edad avanzada, por lo que ya no ejercía su antiguo oficio de zapatero; preguntado por Hernando González de Bliecos que cómo le iba, le habría respondido que

«mal, que he perdido mi hazienda y he perdido mi Ley»" ${ }^{11}$

lo que hacía referencia, en opinión de Hernando González de Bliecos, a su conversión del judaísmo al cristianismo.

Al profundo desconocimiento de la religión cristiana por parte de los judeoconversos recientemente convertidos se unía una indisimulada resistencia a reconocer al cristianismo como superior al judaísmo. García López, vecino de Soria y sastre de profesión, convertido al cristianismo con toda probabilidad en 1492, a la salida de la misa del primer día de la Pascua de Navidad del año 1498, y debido a que el clérigo oficiante había anunciado las fiestas de guardar de la semana, habría afirmado que

C. Carrete, op. cit., n. ${ }^{\circ} 308$, p. 131.

9 Parece significativa la estancia de la mujer de Alonso López en Ciudad Rodrigo, población muy próxima a la frontera con Portugal, quizá con la intención de pasar a este reino ante la eventualidad de cualquier posible sospecha hacia su persona por parte de la Inquisición.

10 C. Carrete, op. cit., n. ${ }^{\circ} 237$, p. 109.

11 C. Carfete, op. cit, n. ${ }^{\circ} 428$, p. 175. 
«agora vos digo que nunca creý que hera peor de levar el bien quel mal; quando héramos judíos enojávomonos con una pascua que vernía de año a año, y agora cada día pascua e fiesta carga e soberval, pues la misa que oymos se lo vale, que no entendemos más que asnos ${ }^{12}$, e este abad que la dize que juro a Dios que creo que no sabe más que aquel perro; y agora es el catyverio verdadero, que aún en su casa el onbre no osa hablar, vos juro a Dios, para su mujer, ni menearse, que algunos días de las fiestas menores haré alguna cosa ençerrado en mi casa, syno pedimientos; que no oso que antes heran ellas subjetas de nosotros; agora somos nosotros dellas. $E$ quando héramos judios héramos señores; agora somos catyvos. Lo qual dezya a un Diego Sánchez, christiano nuevo, defunto, que avía seydo rabí de su sinagoga» ${ }^{13}$.

No obstante, pese a la inicial y tenaz resistencia oculta hacia el cristianismo, el paso del tiempo y, especialmente, la práctica de la nueva religión llevó a numerosos judeoconversos a profesar de forma sincera el cristianismo. Es el caso de Juan Cristiano, vecino de Langa de Duero y sastre de profesión, quien en cierta ocasión habría manifestado

«que avían pasado bien diez años, después que se tornó christiano ${ }^{14}$, que le pesava por se aver tornado christiano, que no estava en sí en aquel tienpo de aquellos diez años, pesándole por ser christiano, pero que ya era buen christiano y estava contento ${ }^{15}$.

Además de los citados hasta aquí, existe constancia documental de la conversión al cristianismo en 1492 de otros diversos judíos que residían en distintas localidades de la diócesis de Osma. Son éstos los siguientes:

- Ysaque Aselor, trapero, vecino de Berlanga de Duero, quien en 1492 tomó el nombre de Diego López. Unos años después fue procesado por la Inquisición ${ }^{16}$.

- Yuçe Çelemín, "escribano de mano» ${ }^{17}$, vecino de Soria, quien cuando fue decretada la expulsión de los judíos se convirtió al cristianismo tomando el nombre de Alonso de San Clemente ${ }^{18}$.

- Abrahén Alvo, vecino de Soria en julio de 1490, y casado con Jamila. Al convertirse tomó el nombre de Antonio de Morales y se trasladó

\footnotetext{
La falta de comprensión se debía, con toda probabilidad, a que la misa se decía en latín.

C. Carrete, op. cit., n. ${ }^{\circ} 364$, p. 149.

Sin duda en 1492.

C. Carrete, op. cit., n. ${ }^{\circ} 443$, p. 182.

C. Carrete, op. cit., n. ${ }^{\circ} 109$, p. 57 y n. ${ }^{\circ} 132$, p. 71.

Es decir, mero escribiente, sin capacidad legal para dar fe del contenido de los escritos.

8 C. Carrete, op. cit., n. ${ }^{\circ} 69$, p. 44 y n. ${ }^{\circ} 368$, p. 151.
} 
a vivir a Aranda de Duero, ciudad en la que actuaba como criado de Pero de Santacruz, también judeoconverso y procesado por la Inquisición ${ }^{19}$.

- Don Jacob, quien solía vivir en San Esteban de Gormaz. Se convirtió al cristianismo con el nombre de Pero Carrillo, y desde entonces residía en El Vingo o en San Esteban de Gormaz ${ }^{20}$.

- Rabí Salomón, médico, vecino de Aranda de Duero. Al convertirse en 1492 al cristianismo tomó el nombre de maestre Antonio. Algunos años después fue procesado por la Inquisición ${ }^{21}$.

- Yuçe Lavan, médico, vecino de Roa, quien tomó el nombre de maestre Carlos ${ }^{22}$.

- Diego Calderón, escribano, vecino de Coruña del Conde. De judío había sido criado de don Bueno, judío vecino también de Coruña del Conde, en cuya representación había acudido, en torno al año 1488, a la localidad burgalesa de Mansilla de Burgos, próxima a Salas de los Infantes, para cobrar cierta cantidad de maravedíes correspondiente a las alcabalas de dicha localidad, que don Bueno tenía arrendadas ${ }^{23}$.

- Juan Álvarez, vecino de Soria. Cuando fue publicado el decreto de expulsión procedió a vender unas casas que poseía en esa ciudad. Más tarde, y sin llegar a salir del reino de Castilla, optó por convertirse al cristianismo, tratando de recuperar dichas casas; en virtud de una sentencia del Consejo Real, podría hacerse nuevamente con ellas retornando a sus compradores las cantidades que éstos le habían pagado, así como compensándoles por las mejoras que hubieran podido hacer en las mismas ${ }^{24}$.

- Esther, llamada de cristiana María Arias, vecina de Coruña del Conde. Tanto a ella como a su hijo Mosé Almaner y a Ysaque y Abrahán Aljamín, vecinos de Coruña del Conde y de Peñaranda de Duero, reclamaba el licenciado Fernán González de Ortega, vecino de Olmedo, la cantidad de ciento dieciséis mil quinientos maravedíes, en su calidad de herederos y detentadores de los bienes de Saúl Aljamín y de su mujer Urosol, por unas obligaciones que tenía sobre ellos. La sentencia de la

\footnotetext{
C. Carrete, op. cit., n. ${ }^{\circ}$, pp. $19-20$ y n. ${ }^{\circ} 427$, p. 175.

C. Carrete, op. cit., $\mathrm{n}^{\circ} 349, \mathrm{pp} .142-143$.

C. Carrete, op. cit., n. ${ }^{\circ} 159$, p. 82 y n. ${ }^{\circ} 194$, p. 94.

22 Archivo Histórico Nacional, Inquisición de Toledo, leg. 133, núm. 47. Fritz BaER, Die Juden im Christichen Spanien. l/2. Kastilien/Inquisitionakten. Berlín, 1936 (reimp. Gregg International Publishers Limited. England, 1970), p. 526.

23 C. Carrete, op. cit., n. ${ }^{\circ} 429$, p. 176.

24 Archivo General de Simancas (en adelante AGS), Registro General del Sello (en adelante RGS), fol. 73; documento de 12 de mayo de 1493.
} 
Notas acerca de la expulsión de los judíos en la diócesis de Osma (Soria)

Real Chancillería ordena que se guarde la avenencia e iguala entre ambas partes ${ }^{25}$. La persistencia del nombre hebreo es un posible indicador de la no conversión al cristianismo y, por tanto, de la salida del reino de Mosé Almaner y de Ysaque y Abrahán Aljamín, pero nada seguro puede decirse al respecto.

- Diego Sánchez, vecino de Gumiel de Mercado. Él y su hija se convirtieron al cristianismo en 1492; sin embargo el marido de ésta, Moisés Hen, vecino de Coruña del Conde, se marchó a Portugal, donde murió judio ${ }^{26}$.

- La mujer de Yonahán Michi, pergaminero y shamash ${ }^{27}$ de la sinagoga de Soria. En 1502, ya viuda y vieja, vivía en Almazán ${ }^{28}$. Desconozco la actitud de Yonahán Michi ante la promulgación del decreto de expulsión, aunque cabe pensar que, si vivía para entonces, también se convirtiera al cristianismo.

Las tensiones entre cristianos y judíos en los años inmediatamente precedentes a la promulgación del decreto de expulsión se prolongaron durante algún tiempo en las relaciones entre cristianos viejos y cristianos nuevos, ya que éstos eran vistos cada vez con mayor recelo por parte de aquéllos, lo que era causa de frecuentes roces. Esta enemistad se expresaba en la mayor parte de las ocasiones en el insulto y el desprecio hacia los nuevos convertidos al cristianismo, lo que obligaba a intervenir con frecuencia a las autoridades regias. De este modo, el 27 de octubre de 1493 el Consejo Real se dirigía a los corregidores, alcaldes y otras justicias cualesquier de las ciudades, villas y lugares de los obispados de Cuenca, Osma y Sigüenza, y les ordenaba castigar a quienes insultaran a los judíos recientemente convertidos al cristianismo llamándoles «judíos», «tornadizos» y otros diversos insultos de similar significado, motivo por el que, según decían, no se atrevían a salir de sus casas ${ }^{29}$. Este documento invita también a pensar en la importancia cuantitativa de la conversión de judíos en 1492.

3. Pese a todo, parece indudable que la mayor parte de la población hebrea se mantuvo fiel a la religión judía, en lo que por una parte influyó el

\footnotetext{
25 Archivo de la Real Chancillería de Valladolid, caja 49, n. ${ }^{\circ} 11$. María Antonia VaronA, «Pleitos de judios en la Real Chancilleria de Valladolid. Regesta de sus cartas ejecutorias (14861495) », en Sefarad, LIV (1994), pp. 155-193.

26 AGS, RGS, fol. 299; documento de 22 de marzo de 1493. Luis SUÁREZ FERNÁNDEZ, Documentos acerca de la expulsión de los judios. Valladolid. CSIC, 1964, pp. 509-510.

27 Textualmente, "criado» o «sirviente». Así se denomina al bedel o ujier de la sinagoga, especie de sacristán, quien, a cambio de un salario, se ocupa de todos los menesteres de la misma, excepto de los que corresponden al rabi.

28 C. CaRReTE, op. cit., n. ${ }^{\circ} 27$, pp. $30-31$ y n. ${ }^{\circ} 145, p .76$.

29 AGS, RGS, fol. 146; documento de 27 de octubre de 1493.
} 
apego a las creencias y a las tradiciones heredadas de sus antepasados, y por otra, en no menor medida, el temor que les inspiraba la Inquisición; no en vano, una vez convertidos al cristianismo, los judeoconversos quedaban sometidos a la jurisdicción del Tribunal del Santo Oficio, una vez transcurrido el plazo «de gracia» que se les concedió para que se adaptaran a su nueva condición de cristianos. Especialmente significativa es a este respecto la testificación que el día 10 de marzo de 1502 hizo ante el Tribunal de la Inquisición, en Aranda de Duero, Juan de Salzedo, cristiano nuevo vecino de Soria; este interesante personaje ${ }^{30}$ declaró que el día de la «Pascua del pan cenceño" " ${ }^{31}$ del año 1492, unos días después de que los Reyes Católicos hubieran ordenado la salida de los judíos de sus reinos, se encontraba en la casa de Ysaque «el portugués», también vecino de Soria, quien estaba enseñando a un hijo suyo a «meldar» ${ }^{32}$, ante lo que Fernando de Guernica, judeoconverso vecino de Soria, le había dicho que

\begin{abstract}
«faríades mejor de entender, aunque sea Pascua o sea nada, en cómo avés de poner cobro en vuestra hazienda e cómo vos avés de yr, que aunque algunos os dizen que os tornés christianos, mala Pascua me dé Dios sy yo os lo aconsejo. El por qué es que, acabado que seáys christianos, luego buscarán por dónde den con vosotros de rostros en el fuego; que mientras que este diablo biviere, que en ora mala entró en Castilla, lo qual dixo por el rey, nuestro señor, con quanto poder tiene no le fartará el Hermandad, el Santa Ynquisiçión, el Santa Cruzada; y dígos que no os cunple tornaos christianos por la razón que he dichos ${ }^{33}$.
\end{abstract}

El decreto de expulsión concedía a los judíos que no se convirtieran al cristianismo un plazo de tres meses para abandonar el reino. Durante este tiempo, los reyes tomaron bajo su amparo y protección a los judíos, y les concedieron licencia para vender y permutar todo tipo de bienes, muebles y raíces. Buen ejemplo de ello es la carta que el 24 de mayo de 1492 se dirigió desde el Consejo Real a las autoridades de las villas de Gumiel de Mercado y Gumiel de Izán, ordenándoles que no consintieran que se pusiera ningún tipo de impedimentos a rabí Yuda, a su hermano Yuçe de Soto, a Simuel de Soto, a Socorro, a Haze y a Simuel Soer, vecinos de Gumiel de Mercado, para la venta de sus bienes. Al parecer, algunas personas habían

30 Juan de Salzedo, llamado de judío rabí Yantó, es uno de los principales judeoconversos sorianos del período de tránsito entre los siglos $\mathrm{xV}$ y $\mathrm{XVI}$, y aparece con suma frecuencia en la documentación inquisitorial del obispado de Osma, testificando en contra de numerosos supuestos judaizantes.

31 Se refiere a la fiesta de Pesah o de Pascua, en la que los judios deben consumir pan ázimo o «cenceño», es decir sin levadura.

32 Es decir, a rezar.

33 C. Carrete, op. cit., n. ${ }^{\circ} 373$, p. 155. 
extendido interesadamente el rumor de que los reyes habían prohibido la compra de bienes de los judíos, a fin de que se marcharan sin haber podido venderlos $\mathrm{y}$, de este modo, hacerse con ellos ${ }^{34}$.

Pese a que da la impresión de que, en general, los judíos no tuvieron excesivas dificultades para la venta de sus bienes en las distintas localidades de la diócesis de Osma en las que residían, la exigüidad del plazo para abandonar el reino favoreció la actuación de algunos especuladores que, aprovechándose de la situación, adquirieron bienes de los judíos por mucho menos de su valor real. Debido a la prohibición de sacar del reino oro, plata, moneda amonedada, joyas, armas y caballos, la transacción más frecuentemente utilizada fue la letra de cambio, que financieros y mercaderes hacían efectivas a los judíos en sus puntos de destino. Pese a todo, debieron ser bastantes los judíos que incumplieron dicha prohibición, contando para ello con la ayuda de algunos cristianos; de este modo, el día 6 de septiembre de 1492 el Consejo Real dictó una carta a las autoridades locales de diversas ciudades y villas del reino, ordenándoles que actuaran contra los cristianos que aceptaban dinero de los judíos a cambio de su ayuda para sacar del reino oro y plata. Una de estas cartas fue dirigida a las autoridades de la ciudad de Soria ${ }^{35}$.

Sumamente complejo fue el problema que se planteó en relación con los contratos de préstamo, debido a que el decreto de expulsión cogió a numerosos judíos en situación de acreedores o de deudores, y a que el plazo para hacer efectiva la cantidad adeudada vencía en muchos casos después de la fecha última fijada para la salida de los judíos del reino, es decir el 31 de julio de 1492. La mayor parte de las contratos de deuda en los que los judíos aparecían como acreedores no se hicieron efectivos antes de su salida del reino, sino que, a cambio de una compensación económica, fueron traspasados a cristianos. Los ejemplos son numerosos: el 29 de julio de 1492 el Consejo Real se dirigió a las autoridades de la ciudad de Soria y les ordenó que no hicieran ejecutar los contratos de préstamo que algunos vecinos de Villoslada, Lumbreras y Ortigosa, localidades sujetas al señorío del duque de Nájera y ubicadas en la riojana comarca de Cameros, habían suscrito con la aljama de los judíos de Soria y que, posteriormente, se habían traspasado a algunos cristianos y mudéjares particulares, hasta que se comprobara si en dichos contratos había mediado usura ${ }^{36}$.

\footnotetext{
34 AGS, RGS, fol. 532; documento de 24 de mayo de 1492. Luis SuÁREZ FERNÁnDEZ, Documentos acerca de la expulsión de los judios, pp. 414-416.

35 AGS, RGS, fol. 228; documento de 6 de septiembre de 1492. Luis SuÁREZ, op. cit, pp. $465-467$.

36 AGS, RGS, fol. 89; documento de 29 de julio de 1492. Luis SuÁREZ, op. cit., pp. 453-454.
} 
Los pleitos que surgieron en torno a estas cuestiones debieron alcanzar tal magnitud que el día 10 de septiembre de 1492 los Reyes Católicos se vieron obligados a hacer pública una disposición general, según la cual se procedía a dejar en suspenso todos los contratos de préstamo que los judíos habían traspasado a cristianos al tiempo de la expulsión, hasta que por parte del Consejo Real se determinara lo que procedía hacer al respecto; el procedimiento consistió, normalmente, en la designación de alguna persona que investigara acerca de la licitud o ilicitud de los contratos. En esta línea, el 30 de enero de 1493 el Consejo Real comisionaba al lugarteniente del corregidor de Soria a fin de que investigara acerca de la licitud de ciertos contratos que unos judíos de Soria habían suscrito con algunos vecinos de la localidad soriana de Serón y que, posteriormente, habían traspasado a ciertas personas poderosas, que no se nombran ${ }^{37}$. Algún tiempo después, el 7 de abril del mismo año, el Consejo Real comisionaba al bachiller Portillo para que, en compañía de Francisco de Tapia, corregidor de la ciudad de Soria, juzgara la licitud de los contratos que ciertos judíos habian traspasado al conde de Monteagudo ${ }^{38}$.

Hubo también algunos judíos que, fuera porque no tuvieron posibilidad de hacer efectivos o de traspasar los contratos de deuda en los que figuraban como acreedores, o fuera porque tenían la intención de aceptar el bautismo, los conservaron en su poder. $Y$ una vez convertidos al cristianismo y, en algún caso, retornados al reino desde Portugal, reclamaron de sus deudores el cumplimiento de dichos contratos. Especialmente significativa es a este respecto la declaración que el día 12 de enero de 1502 hizo ante el Tribunal de la Inquisición Juan de las Cámaras, vecino de Aranda de Duero, quien afirmó haber oído decir a Pero Núñez de Santa $\mathrm{Fe}$ «el Ronquillo», judeoconverso vecino de Coruña del Conde, que

«sy no fuera por las debdas que le devían, que no se tornara christiano ni viniera de Portugal $2{ }^{39}$.

El problema era aún mayor, no obstante, cuando los acreedores de los contratos de préstamo eran cristianos. En estos casos se procedía al nombramiento por parte del Consejo Real de jueces compromisarios que valorarían los bienes de los judíos deudores, compensando con ellos la deuda. También fue frecuente que los judíos, en compensación por sus

37 AGS, RGS, fol. 74; documento de 30 de enero de 1493

38 AGS, RGS, fol. 78; documento de 7 de abril de 1493.

39 C. Carrete, op. cit., n. ${ }^{\circ} 231$, p. $107 ;$ n. $^{\circ} 305$, p. $129 ;$ n. $^{\circ} 306$, p. $130 ; y$ n. ${ }^{\circ} 308$, p. 131. 
Notas acerca de la expulsión de los judios en la diócesis de Osma (Soria)

deudas, traspasaran a sus acreedores cristianos otras cartas de deuda en las que ellos figuraban como acreedores.

En definitiva, y pese a la protección regia de que disfrutaron hasta su salida del reino, es fácil comprender las angustias sufridas por los judíos en las fechas previas a su partida. Si por un lado eran forzados por sus acreedores a satisfacer las deudas que con ellos tenían, por otro lado no conseguían fácilmente cobrar aquellas otras que a ellos se les debían, ya que sus deudores les daban largas con la esperanza de que, entre tanto, les llegara la hora de la partida. Buen ejemplo de ello es la amarga queja de los judíos de Calatañazor ante el Consejo del Norte de los Puertos, en la que se esforzaban por hacer comprender que era más justo que se les pagaran a ellos las deudas que se les debían, que no a la inversa, por cuanto sus acreedores cristianos podrían ir a buscarlos alli donde se fueran, en tanto que ellos no podrían volver a Castilla pasados los tres meses concedidos en el decreto de expulsión para abandonar el reino ${ }^{40}$. Parecida queja es la que formularon, por las mismas fechas, don Simuel de Soto y sus hijos rabí Simuel y rabí Aby, vecinos de Aranda de Duero, quienes recurrieron ante el Consejo Real alegando que sus deudores se negaban a hacer efectivos los contratos de préstamo cuyos plazos vencían con posterioridad a la salida de los judíos del reino, en tanto que sus acreedores, con el fin de hacerse con sus bienes por mucho menos de su valor real, se negaban a recibir a cambio de las deudas que tenían con ellos otras cartas de deuda en las que don Simuel de Soto figuraba como acreedor. La sentencia del Consejo Real fue la habitual en este tipo de pleitos: se comisionó al bachiller Alonso de Torres, vecino de Aranda de Duero, para que nombrara dos personas, una a propuesta de cada una de las partes, que tasarían los bienes muebles y raíces de don Simuel de Soto y de sus hijos, y que habrían de ser aceptados por los acreedores en compensación de las deudas que con ellos tenían. Asimismo se concedía a estos judíos una carta de seguro, para sus personas y bienes, durante los tres meses que mediaban hasta su salida del reino ${ }^{41}$.

Parecidas tretas debían ser también empleadas por los judíos, como se deduce de diversos testimonios documentales. De este modo, el 17 de mayo de 1492 el Consejo del Norte de los Puertos se dirigía a los alcaldes de la

40 AGS, RGS, fol. 327; documento de 25 de mayo de 1492.

41 AGS, RGS, fol. 331; documento de 8 de mayo de 1492. Enrique CanTERA MonTEnEGRo, «Una familia de prestamistas y arrendadores judios en tiempos de la expulsión: los Soto de Aranda de Duero", en Espacio, Tiempo y Forma, 12 (1999), pp. 11-46 (en concreto, pp. 21-22 y 35-38). 
villa de Aranda de Duero y les ordenaba que vieran la queja presentada por Garci Sánchez de Calahorra, y sus hermanos menores, contra don Yuçe de Soto, vecino de la misma localidad, quien les debía ciertas cantidades de maravedíes y una taza de plata, y que continuamente les daba largas para devolvérselas, con la intención de que, entre tanto, llegara la fecha para salir del reino ${ }^{42}$.

Finalmente, después de vender sus propiedades de la mejor manera que pudieron, los judíos salieron en su mayor parte hacia el vecino reino de Portugal. En menor número, algunos otros se dirigieron hacia Navarra, o hacia Cartagena, donde embarcaron en dirección al Magreb, a Italia o al Próximo Oriente. Muy gráfica al respecto es la declaración que el 24 de febrero de 1502 hizo ante el Tribunal de la Inquisición Francisco del Águila, judeoconverso vecino de San Esteban de Gormaz, quien afirmó que haría nueve o diez años, al tiempo que los judíos salieron del reino, Juan de León «el Viejo», vecino de San Esteban, le preguntó que a dónde pensaba ir, y

«este testigo le dixo cómo acordavan de yr por Portugal, e cómo otros dezían que hera bueno yr por Cartajena» ${ }^{43}$.

Entre los judíos que se dirigieron hacia el Próximo Oriente merece ser destacado Juda Bienveniste, vecino de Soria, quien se estableció en la ciuciad griega de Salónica, donde iba a constituirse una muy importante comunidad sefardi ${ }^{44}$. Fijada aquí su residencia ${ }^{45}$, puso su extraordinaria biblioteca particular a disposición del rabino Jacob ben Habib, judío de Zamora, establecido también en Salónica, y autor de unos estatutos o Taqqanoth para la comunidad sefardí de esta ciudad, consistentes en un compendio de Respuestas, cuya finalidad era resolver los numerosos

42 AGS, RGS, fol. 657; documento de 17 de mayo de 1492. Enrique CANTERA, op. cit., pp. 3839.

43 C. CARRETE, op. cit., n. ${ }^{\circ} 369$, p. 153.

44 Para profundizar en el conocimiento de la comunidad hebrea de Salónica puede acudirse a los estudios de I.-S. Emmanuel. Histoire des Israélites de Salonique, t. 1 (140 av. J.-C- à 1640), París, 1936 (en particular los capítulos il: «Expulsion des israélites d’Espagne, du Portugal et d'Italie (1492-1510)»; III: "La civilisation judéosalonicienne après l'installation des Juifs espagnols, portugais et italiens (1500-1550)»; y IV: «Heurs et malheurs de la communauté de Salonique après l'expulsion d'Espagne jusqu'à l'époque de Samuel de Médina (1510-1550)"); Joseph NeHAMA, Histoire des Israélites de Salonique, 7 vols. (interesan los vols. I al IV, París, 1935-1936); y Michael Molho, Usos y costumbres de los Sefardíes de Salónica, Madrid-Barcelona, CSIC, 1950.

Asimismo, el muy útil Dictionnaire du Judéo-Espagnol de Joseph NEHAMA y Jesús CanTERA (Madrid, CSIC, 1977) se basa, en buena medida, en el ladino hablado por los sefardíes de Salónica.

45 Posiblemente, tras una breve estancia de ocho meses en Portugal y otra algo más prolongada en el Magreb. 
problemas derivados de la inmigración sefardí, pero que, lamentablemente, no se han conservado; asimismo es autor ben Habib de un compendio de Midrashim llamado En Jaacob ${ }^{46}$.

Pero son más abundantes las noticias que se han conservado acerca de los judíos que pasaron a Portugal, reino en el que se autorizó el establecimiento de los judíos castellanos durante un período de ocho meses, a cambio del pago de ocho cruzados por cabeza. Entre los judíos residentes en localidades de la diócesis de Osma de los que se tiene constancia documental de su paso al reino vecino cabe destacar a los siguientes:

- Don Jaco Aben Simón, vecino de Aranda de Duero, quien más tarde fijo su residencia en Torregalindo, pequeña localidad situada a unos $10 \mathrm{ki}-$ lómetros al suroeste de Aranda, de donde partió hacia el exilio en 1492. Se dedicaba al préstamo con interés, pues consta documentalmente que había efectuado un préstamo de cinco mil maravedíes a García de Almoguera, vecino de Aranda de Duero, por el que, según la queja de éste, le había llevado usura. Al salir del reino, sus bienes fueron incautados por el alcaide de la fortaleza de Torregalindo, hallando entre sus escrituras la carta de deuda de García de Almoguera con don Jaco, por lo que el alcaide pretendía hacerla efectiva, pese a que aquél insistía en que ya había sido satisfecha ${ }^{47}$.

- Ysaque «el Poriugués», vecino de Soria. Con su mujer, su suegra y un hijo de corta edad pasó a Portugal en 1492, no regresando. Era tintorero de profesión, pues cuando salió del reino hacia el exilio dejó un "tynte... con todo su aparejo" a Fernando de Guernica «el Viejo», calderero, de quien era muy amigo, según testifica Juan de Salzedo ante el Tribunal de la Inquisición el día 10 de marzo de 1502:

«e dezyan que ge lo dexó porque hera su amigo, e porque le avía de levar los dineros dello a Portugal»" ${ }^{48}$.

- También pasó a Portugal el padre de Cristóbal Cubero, cristiano nuevo vecino de Soria. Juan de Salzedo, casado con la mujer de Cristóbal Cubero, declaró el día 10 de marzo de 1502 ante el Tribunal de la Inqisición que veía con frecuencia a su cuñado preparar la adafina ${ }^{49}$ los

46 I.-S. Emmanuel, Histoire des Israélites de Salonique, pp. 85-87, y suplemento final sobre «L'histoire de l'Industrie des Tissus des Israélites de Salonique», p. 9.

47 AGS, RGS, fol. 263; documento de 4 de septiembre de 1492.

48 C. CARRETE, op. cit., n. ${ }^{\circ} 373$, pp. 155-156.

49 Así denominaban los judíos españoles al hamín, es decir el guiso a base de carne, verduras y legumbres que preparaban los viernes antes de la puesta del sol, y que dejaban cubierto de brasas y rescoldos para que se mantuviera caliente hasta la comida del shabbat. 
viernes por la noche, y que cuando le preguntaba si aquello lo confesaba o lo hacía con licencia, le respondía:

«No cures vos de mi alma que, como dezya mi padre cuando se yban a Portugal: "Esto el Dio barohú (= Baruk hu= Bendito Él) lo ha de librar". Lo qual vio de çinco años a esta parte, porque de antes no hera casado el dicho Cristóbal, que hera moço d'espuelas de Yñigo López de Mendoça» ${ }^{50}$.

Con mucha frecuencia el decreto de expulsión de 1492 dividió las familias judías, de forma que si unos de sus miembros optaron por la conversión al cristianismo, otros prefirieron salir del reino. En este caso concreto que nos ocupa, en tanto que el padre optó por el exilio, el hijo (llamado de cristiano Cristóbal Cubero) se convirtió al cristianismo o regresó convertido de Portugal.

- Muy similar es el caso del suegro de Andrés Muchos, cristiano nuevo vecino del Burgo de Osma, zapatero de profesión. El día 26 de enero de 1502 Catalina de Salmerón, mujer de Alonso Díaz, mercader vecino del Burgo de Osma, declaró ante el Tribunal de la Inquisición que en el verano último, hablando un dia con la mujer de Andrés Muchos le preguntó

«sy en Portugal sy avía muerto su padre seyendo judío, e respondió que sy, e mostró, a paresçer deste testigo, plazer dello. E este testigo le preguntó e dixo: “¡Ay, Santa María! ¿Y plazéos dello?”, e la... susodicha dixo: “¡Ha, no va nada en ello!", mostrando más plazeres de antes. E no pasó más por entonçes. $\mathrm{E}$ que non lo dize por odio» ${ }^{51}$.

- También marcharon a Portugal, probablemente, don Ça Çabaco y don Jaco Abrahén, vecinos de Coruña del Conde, quienes fueron nombrados fiadores en el arrendamiento de las tercias de los arciprestazgos de Osma, Coruña y Cabrejas con Guzmán, del año 1491, que hizo Miguel García, vecino de esta misma localidad, a García Fernández de Chaves, en nombre de Fernand Núñez Coronel. Se quejaba Miguel García de que las personas que debían alguna cantidad de dichas rentas no querían pagarla, alegando que eran deudas de judíos y que sobre ellas se había puesto embargo por orden regia ${ }^{52}$. El hecho de que el documento, de febrero de 1494, cite a don Ça Çabaco y a don Jaco Abrahén por su nombre hebreo hace pensar en que no debieron convertirse al cristianismo en 1492.

so C. Carrete, op. cit., n. ${ }^{\circ} 373$, pp. 155-156.

51 C. CARRETE, op. cit., n. ${ }^{\circ} 241$, p. 110.

52 AGS, RGS, fol. 327; documento de 8 de febrero de 1494. 
- Personaje de gran relevancia fue don Abraham Bienveniste de Calahorra, vecino de Soria, quien también pasó a Portugal en 1492. Personaje poderoso económicamente, se dedicaba, entre otras actividades, al comercio de lanas, acudiendo a las ferias de Medina del Campo. En las fechas inmediatas a la salida de los judíos del reino mantenían pleito con él Juan Alonso de Sahagún y su hijo Andrés de Escobar, mercaderes vecinos de Burgos, quienes se quejaban de un supuesto fraude que les habría hecho Abraham Bienveniste en los contratos de mercancías de lana que mantenían desde hacía veinte años; la cuantía de estos contratos se elevaba a un millón y medio de maravedíes anuales, y el fraude ascendería a tres millones de maravedíes. Dichos mercaderes manifestaban que era público y notorio que Abraham Bienveniste estaba huido y que se marchaba del reino, que no había ninguna esperanza de que retornara, y que había vendido ya toda su hacienda, igualándose con sus deudores y acreedores; por todo ello, solicitaban que se le exigiera la entrega de fianzas hasta en cuantía de tres millones de maravedíes y que, en caso de que no lo hiciera, que se le prendiera y se procediera al embargo de sus bienes. El caso fue encomendado por el Consejo Real a Alfonso de Quintanilla, contador mayor de cuentas y miembro del Consejo Real, y a Francisco Triguero, alcalde mayor de la Hermandad ${ }^{53}$, quienes debieron sentenciar favorablemente a los intereses de Juan Alonso de Sahagún y de Andrés de Escobar. Así sabemos que, con fecha de 22 de marzo de 1493, el Consejo Real había ordenado el embargo de todos los bienes y de ciertas escrituras y cartas de obligación que don Abraham Bienveniste de Calahorra había dejado en poder de dichos mercaderes burgaleses, hasta tanto que se averiguara si era cierta la acusación que pesaba sobre el judío de haberse llevado a Portugal oro, plata y otras cosas prohibidas ${ }^{54}$. La información debió resultar positiva, ya que el 30 de abril de 1495 el Consejo Real ordenó a Fernando Gómez de la Cueva, receptor de los bienes y cartas de deuda que los judíos habían dejado en la ciudad de Soria y en el obispado de Osma, que tomara todos los libros, contratos y escrituras que don Abraham Bienveniste había dejado en poder de Juan Alonso de Sahagún y de Andrés de Escobar. Asimismo se levanta el embargo que pesaba sobre los bienes y cartas de deuda dejadas por don Abraham Bienveniste, y se ordena a los corregidores de las ciudades de Burgos y Soria que obligaran a que fueran pagadas a Fernando Gómez de la

53 AGS, RGS fol. 290; documento de 28 de junio de 1492.

54 AGS, RGS, fol. 276; documento de 22 de marzo de 1493. 
Cueva todas las cantidades que se debieran a dicho judío por contratos lícitos de deuda ${ }^{55}$.

El embargo de los bienes de Abraham Bienveniste dio lugar a quejas por parte de diversas personas que tenían contratos firmados con dicho judío antes de la expulsión, y que de este modo no podían hacerlos efectivos. Entre éstos estaba Antón Fernández de Morales, escribano público de número y vecino de la ciudad de Soria, quien se quejaba de que, al tiempo que se había marchado del reino, Abraham Bienveniste le debía cerca de veinte mil maravedíes, por ciertas lanas y por otros derechos, pero que no lograba que el receptor de los bienes de los judíos en Soria los hiciera efectivos en los bienes que dicho judío había dejado en esta ciudad y en su tierra y términos. El asunto fue cometido por el Consejo Real al bachiller Diego de Salmerón, corregidor en la ciudad de Soria y juez de los bienes de los judíos pertenecientes a la Cámara y fisco real ${ }^{56}$.

Asimismo tuvo compañía mercantil con Francisco de las Eras, mercader vecino de Soria. Juntos compraron lana de ciertos vecinos de Lumbreras, Villoslada y Las Tenas, lugares del señorío del duque de Nájera ubicados en la comarca riojana de Cameros, y pagaron por ella ciento veinticinco mil maravedíes. Más tarde, cuando fueron expulsados los judíos del reino, Abraham Bienveniste había vendido a Francisco de las Eras su parte de dichas lanas, pero éste se quejaba de que, a pesar de que las mismas ya habían sido pagadas, los vendedores no le querían hacer entrega de la mercancía ${ }^{57}$.

Los judíos contaron con el seguro y protección de las autoridades regias hasta el mismo momento de abandonar el reino. Incluso fue frecuente que personas designadas por los reyes o por el Consejo Real acompañaran a los miembros de alguna relevante familia o, con mayor frecuencia, a los vecinos de una o más poblaciones hasta la misma frontera, a fin de garantizar la seguridad de sus personas y bienes. Así, el 22 de mayo de 1492 el Consejo del Norte de los Puertos comisionaba al bachiller Alonso de Torres, vecino de Aranda de Duero, para que acompañara hasta la frontera a don Simuel de Soto y a sus parientes, amigos y criados judíos de esta población ${ }^{58}$.

55 AGS, RGS, fol. 392; documento de 30 de abril de 1495.

56 AGS, RGS, fol. 325; documento de 28 de julio de 1495

57 AGS, RGS, fol. 297; documento de 13 de mayo de 1493.

58 AGS, RGS, fol. 526; documento de 22 de mayo de 1492. Luis SUÁREz, op. cit., pp. 408-411; Enrique Cantera, op. cit, p. 23. 
Sin embargo, las cartas de seguro regias no fueron suficientes para impedir los asaltos contra judíos en las fechas previas a su salida del reino, o cuando se dirigían ya hacia Portugal. El 5 de junio de 1492 el Consejo del Norte de los Puertos ordenaba a las justicias de Calatañazor, a petición de Ysaque Beque y de la aljama de los judíos de dicha localidad, que pusieran en libertad a los hermanos e hijos del demandante, así como a otros judíos de la aljama, y que devolvieran a Ysaque Beque cuarenta paños que le habían sido tomados cuando, en compañía de sus hermanos, los llevaba a vender, con otras diversas mercancías, a la feria de Medina del Campo, preparando su próxima salida del reino ${ }^{59}$. Del mismo modo, en octubre de 1494 los reyes ordenaban al Justicia Mayor del reino y a los miembros del Consejo Real, así como a los oidores de la Audiencia, a los alcaldes y alguaciles de la Casa, Corte y Chancillería, y a todos los corregidores y demás autoridades de las ciudades de Aranda de Duero y Haza que procedieran a prender y castigar a Juan de Gualda, alcaide de Haza, a Sancho Ruiz, alcaide de La Torre del Monte y vecino de Castrillo, a Alfonso Salmerón, vecino de Fuentecén, y a Juan de Benito, vecino de Haza, quienes habían sido acusados criminalmente por doña Constanza de Avellaneda y por don Martín de Acuña, su marido, por el ataque que hacía dos años habían sufrido unos criados suyos y el judío Abraham Garzón, en el camino real que conduce de Aranda de Duero a Roa; los acusados, armados con diversas armas, arremetieron contra ellos $y$, pese a que les enseñaron la carta de seguro real que llevaba Abraham Garzón, los apalearon y los alancearon, llevándose preso al judío a la localidad de Haza, y dejando malheridos a algunos de los criados que le acompañaban ${ }^{60}$. Por último, en junio de 1492 Salamón Levi, judío de Soria, sufrió el robo de mil trescientos cruzados y doblas de oro en el mesón Ilamado "La Bóveda», en tierra de la ciudad de Salamanca; como estaba obligado a salir del reino de Castilla en fecha próxima, comisionó a una persona para que prosiguiera la causa, y aunque en un principio las sospechas recayeron sobre el mesonero y sobre otras personas de este establecimiento, finalmente la acusación se centró en un pastor, ya que fueron halladas en poder de su madre ciento setenta monedas de oro ${ }^{61}$.

4. Pero algunos meses después de dejar el reino, y como consecuencia de las penurias sufridas en el exilio, algunos judíos se dirigieron a los Reyes Católicos solicitando licencia para regresar. La respuesta fue

59 AGS, RGS, fol. 295; documento de 5 de junio de 1492.

60 AGS, RGS, fol. 441; documento de 30 de octubre de 1491.

61 AGS, RGS, fol. 364; documento de 30 de marzo de 1493. 
afirmativa, de forma que, en virtud de las cartas otorgadas por los reyes, se autorizaba a retornar a todos los judíos que mostraran un acta de bautismo o que se bautizaran en la frontera; y es más, se les concedía la posibilidad de recuperar sus antiguas propiedades que habían vendido al salir del reino, sin otro requisito que devolver a los compradores las cantidades que habían obtenido por ellas y compansarles las mejoras que hubieran podido hacer en las mismas. Fueron muchos los judíos que entre noviembre de 1492 y 1499 regresaron de este modo al reino de Castilla, como consecuencia de las dificultades que conocieron en Portugal y, muy en especial, en las tierras del Magreb. Muy expresiva es la descripción que Juan de San Esteban, judeoconverso vecino de San Esteban de Gormaz, hizo de la situación de los judíos castellanos en Portugal en 1493, cuando dice que

"dellos pasavan allende ${ }^{62}$, según avía oydo dezir, e dellos se tornavan a Castilla; e que los que allá estaban fazyan muchas oraçiones e reclamos a Dios, viendo la perdizión de sus criaturas e de sus personas" ${ }^{63}$.

A las penalidades del exilio se unió también el deseo de recuperar los bienes dejados en sus lugares de procedencia, así como de hacer efectivos los contratos de deuda que la precipitada marcha no les había permitido percibir. Como ya se indicó anteriormente, el 12 de enero de 1501 Juan de las Cámaras, vecino de Aranda de Duero, declaró ante el Tribunal de la Inquisición que en una ocasión había oído decir a Pero Núñez de Santa Fe «el Ronquillo», judeoconverso vecino de Coruña del Conde, que

«sy no fuera por las debdas que le devían, que no se tornara christiano, ni viniera de Portugal» 64 .

Una señal evidente de que el regreso de judíos a las tierras del obispado de Osma fue importante cuantitativamente son algunas referencias genéricas a dicho acontecimiento, que se contienen en documentación inquisitorial. Así, en su declaración del día 12 de abril de 1502 ante el Tribunal de la Inquisición, Juan de Salzedo

«dixo que puede aver fasta nueve años, que al tienpo que se tornaron los judíos de Portugal, que en aquel año o en el segundo este testigo encontró un día, saliendo de la çibdad por la Puerta Rabanera, con Diego López, que bive

62 Al otro lado del mar, es decir al norte de África.

63 C. CarRete, op. cit., n. ${ }^{\circ} 351$, p. 144.

64 C. CaRRETE, op. cit., n. ${ }^{\circ} 231$, p. 107. 
Notas acerca de la expulsión de los judíos en la diócesis de Osma (Soria)

en Verlanga, christiano nuebo, que venía a Soria pocos días avía, e començaron ha hablar este testigo y él e en las cosas de la misa... ${ }^{65}$.

En parecidos términos se expresa María, mujer de Pedro de las Puertas, vecinos de Aranda de Duero, quien en su declaración del día 21 de diciembre de 1500

«dixo que podrá aver ocho años, luego como vinieron los judíos de Portogal, este testigo morava a soldada en la villa de Aranda con Garçía de Contreras, çapatero, e biviendo con él en el dicho tienpo, vinieron dos moços tornadi$z^{6}{ }^{66}$, cada uno de fasta veynte años, e llamavan cada uno Françisco, a casa de... su amo, e los resçibió por aprendices ${ }^{3}{ }^{67}$.

Asimismo, el día 4 de enero de 1502 Antonio Triguero, vecino de Villanueva de Gumiel de Izán hace referencia a una quema pública de libros judíos en la plaza de Coruña del Conde, que habria tenido lugar:

«luego, como vinieron los christianos nuevos de Portogal» 68 .

La documentación ofrece noticias acerca de varios judíos de distintas localidades de la diócesis de Osma que regresaron desde Portugal convertidos al cristianismo. Son, entre otros, los siguientes:

- Francisco Calderón, que contaba en 1500 con unos veinte años de edad y residía en Coruña del Conde, de donde era natural, y donde también vivían su padre y hermanos; fue tomado como aprendiz por el zapatero García de Contreras.

En la declaración que hizo ante el Tribunal de la Inquisición María, mujer de Pedro de las Puertas, se refiere a Francisco Calderón como «tornadizo», lo que puede estar en relación con su posible retorno desde Portugal. Teniendo en cuenta su corta edad, lo más probable es que su marcha a Portugal, y su posterior regreso, fuera en compañía de su padre y hermanos.

Junto a él se cita a otro «tornadizo», también llamado Francisco y de unos veinte años de edad, que fue asimismo tomado como aprendiz por García de Contreras; estaba casado en Pinilla de Trasmonte (localidad burgalesa situada al norte de Aranda de Duero) ${ }^{69}$.

65 C. Carrete, op. cit., n. ${ }^{\circ} 132$, p. 71.

66 El término de «tornadizo» se refiere tanto al neófito al cristianismo, como al que ha tornado o regresado a su antigua ciudad convertido al cristianismo.

67 C. Carrete, op. cit., n. ${ }^{\circ} 176$, p. 88.

68 C. Carrete, op. cit., n. ${ }^{\circ} 200$, p. 96

69 C. Carrete, op. cit., n. ${ }^{\circ} 176$, p. 88. 
- Juan de Cohinbra, «tornadizo» vecino de Fuentenebro (localidad próxima a Torregalindo), y tabernero de profesión. El día 28 de mayo de 1502 Pero Álvarez, vecino de Padilla (localidad próxima a Aranda de Duero), declaró ante el Tribunal de la Inquisición que en una ocasión había oído decir a Juan de Cohinbra que

«mi padre hera judío y mi agüelo hera judío, y no sabe sy dixo "creo" o "entiendo" o "tengo por fe que ellos se an de salvados y otros christianos viejos de condenar"» 70 .

- Fernando, vecino de Coruña del Conde, y hermano de Moisés Hen, quien había muerto judío en Portugal. Moisés Hen se había casado con una hija de Diego Sánchez, cristiano nuevo vecino de Gumiel de Mercado, cuando éste aún era judío. En concepto de dote y casamiento, Diego Sánchez había hecho entrega a Moisés Hen de diversos bienes, hasta en cuantía de treinta mil maravedíes; según la costumbre de los judíos, Moisés Hen había hecho entrega a su mujer del contrato matrimonial (ketubah), entre cuyas cláusulas se establecía el compromiso de restituirle los treinta mil maravedies de la dote y de hacerle entrega, además, de otros quince mil maravedíes de su hacienda, si moría sin haberle dado descendencia. Con motivo de la promulgación del decreto de expulsión, Moisés Hen se marchó a Portugal, donde falleció poco tiempo después, en tanto que su mujer y su suegro se convirtieron al cristianismo, si bien no es posible determinar si su conversión fue previa a su salida del reino o si se convirtieron en Portugal y retornaron más tarde a Castilla. Un hermano de Moisés Hen, que estaba con él en Portugal, se hizo con todos sus bienes muebles y raíces, se convirtió poco tiempo después al cristianismo con el nombre de Fernando, y regresó a Coruña del Conde. $Y$ pese a que Moisés Hen había muerto sin darle descendencia a su mujer, Fernando se negaba a hacer entrega a Diego Sánchez de los cuarenta y cinco mil maravedíes fijados en el contrato matrimonial, por lo que éste se quejó ante la justicia regia ${ }^{71}$.

- Beatriz González, vecina de Ágreda, y su suegro Luis, vecino de Berlanga de Duero, quienes en 1492 habían pasado a Portugal junto con el marido de Beatriz, llamado Ysaque Abenate. Beatriz González era hija de don Liza, judío vecino de Ágreda, un importante personaje que en los años inmediatos a la promulgación del decreto de expulsión tenía arrendadas

C. Carrete, op. cit., n. ${ }^{\circ} 149$, p. 78.

AGS, RGS, fol. 299; documento de 22 de marzo de 1493. 
las rentas de las alcabalas de la villa de Ágreda, al menos de las correspondientes a los años 1488 y $1489^{72}$.

Al poco tiempo de su llegada a Portugal falleció Ysaque Abenate, en tanto que su mujer y su padre se convirtieron al cristianismo y regresaron al reino de Castilla, estableciéndose en Ágreda y en Berlanga de Duero, respectivamente. Algún tiempo después Beatriz reclamaba a su suegro los sesenta mil maravedíes de la dote que había constituido su padre cuando había contraído matrimonio con Ysaque Abenate; al no haber tenido descendencia, Luis se había hecho con los bienes de su hijo, y se negaba a devolver esta cantidad a Beatriz. La sentencia del Consejo Real ordena la devolución de dichos sesenta mil maravedíes a Beatriz González, aunque concede la posibilidad de apelación a Luis ${ }^{73}$.

- Fernando García, vecino de Roa, y linero de profesión ${ }^{74}$. En 1492 pasó a Portugal con su familia, regresando algún tiempo después convertidos al cristianismo. Tenía un hijo llamado Francisco, que en noviembre de 1501 contaba con unos diecisiete años de edad ${ }^{75}$.

- Luis Texeda, vecino de Quintanas de Gormaz (Soria), donde vivía amancebado. El 17 de enero de 1502 Francisco del Águila, cristiano nuevo vecino de San Esteban de Gormaz, declaró ante el Tribunal de la Inquisición que en cierta ocasión Luis Texeda le había dicho que no conservaba testimonio de su conversión al cristianismo ${ }^{76}$, ante lo que él le habría recomendado que fuera a buscarlo a donde le habían bautizado ${ }^{77}$.

- Francisco del Águila, cristiano nuevo vecino de San Esteban de Gormaz. En 1492 pasó a Portugal, de donde regresó convertido al cristianismo; acusado de judaizar, fue procesado por la Inquisición, y en 1502 estaba preso en las cárceles inquisitoriales.

El 24 de febrero de 1502 declaró ante el Tribunal de la Inquisición que haría nueve o diez años, cuando ios judíos salían hacia Portugal, estaba un día hablando con Juan de León «el Viejo», cristiano nuevo vecino de San Esteban de Gormaz, tejedor de profesión, quien le consolaba por su marcha del reino con estas palabras:

\footnotetext{
72 AGS, RGS, fol. 262, documento de 29 de abril de 1491 , y fol. 263 , documento de 30 de abril de 1491.

73 AGS, RGS, fol. 324; documento de 11 de marzo de 1494.

74 Era tratante de tejidos de lino.

75 C. Carrete, op. cit., n. ${ }^{\circ} 319$, p. 134.

76 Se refiere, sin duda, al acta de bautismo que debían presentar en los puestos fronterizos los judíos que regresaban a Castilla convertidos al cristianismo.

77 C. CARRETE, op. cit., n. ${ }^{\circ} 351$, p. 144.
} 
«Pues no estés triste por esta yda vuestra, y pluguiese al Dio que yo fuese vos y vos fuésedes yo, que sois neçio en estar triste por la partyda; que vosotros tragáys la muerte en un trago e nosotros quedamos acá entre esta mala gente, que cada día reçevimos la muerte con ellos; que bien sabes vos que los judíos dezyan: "¡Haba, goym; haba, quelabim!" (= habah, goyim; habah, kelabim = ¡Ea, goyim (= no judíos); ea, perros!). Y que le dixo que le fiziese juramento que no le descubriese esto que le avía dicho; e este testigo le dixo: "¿Cómo lo he de descubrir?, pues yo me voy a la hira del Dio e vos quedáys acá"» ${ }^{78}$.

Del tenor de estas palabras cabe deducir el profundo rechazo que debía producir entre los judíos que dejaban el reino la actitud de quienes en ese momento, o con anterioridad, se habían convertido al cristianismo.

- Don Alazar y Abrahén Romi, hermanos, vecinos de Soria. Se convirtieron al cristianismo en Portugal, y regresaron a su lugar de origen con los nombres de Ruy López de Soria y Gonzalo López. Una vez retornados, reclamaron la devolución de las cantidades con que en 1489 y 1490, siendo judíos, habían contribuido al empréstito que en aquellos años los reyes solicitaron a la aljama de los judíos de Soria y su tierra. En 1489 los judíos sorianos hubieron de hacer frente a dos solicitudes de préstamo, ambas de un millón de maravedíes: en una de ellas don Alazar y Abrahén Romi contribuyeron con veintiún mil maravedíes, y en la otra con dieciséis mil ochenta y cinco maravedíes; este préstamo fue devuelto a los judíos sorianos en $1492{ }^{79}$, pero quizá a causa de su salida del reino don Alazar y Abrahén Romi no habían tenido ocasión de recuperar las cantidades prestadas. En 1490 la cantidad total del préstamo se elevó a quinientos mil maravedies, de los que ambos hermanos hubieron de satisfacer veinte mil seiscientos maravedíes, y otros 900 maravedíes más que pagaron por Symuel, platero ${ }^{80}$.

- Alonso Fernández de la Fuente, cristiano nuevo vecino de Soria, y sastre de profesión. En torno a 1498-1499 tenía alquilado el bajo de la casa de Antón Fernández de Morales, escribano, y de su mujer Inés González de Rueda, vecinos de Soria. Con él vivía un hijo casado, llamado Hernando Álvarez de la Fuente, quien por esas fechas estaba enfermo de bubas ${ }^{81}$.

78 C. Carrete, op. cit., n. ${ }^{\circ} 369$, pp. 153-154.

79 AGS, Estado-Castilla, leg. 1, fols. 116-118. Miguel Ángel LAdERo QueSADA, La Hacienda Real de Castilla en el siglo Xv. Universidad de La Laguna, 1973, p. 325.

80 AGS, Casa y Sitios Reales, leg. 46, fol. 331; documento de 6 de octubre de 1494. Francisco Cantera Burgos, "Conversos y judaizantes en la provincia de Soria», en Homenaje a Vicente García de Diego. Revista de Dialectología y Tradiciones Populares, XXXII (1976), cuadernos 1, 2, 3 y 4, pp. 87-102 (véase p. 97).

81 Enfermedad venérea, también conocida como «mal francés». 
El 1 de septiembre de 1502 Clara, mujer de maestre Alonso, cristiana nueva vecina de Gómara, declaró ante el Tribunal de la Inquisición que, después que regresó convertido de Portugal, Hernando Álvarez le había dicho muchas veces que una de las mancillas que tenía en su corazón era la de haberse vuelto de Portugal; preguntada que qué entendía en lo que le decía Hernando Álvares,

"dixo que entendió que lo dixo porque se avía buelto acá a tornar christiano» 82 .

- Juan García "el Rico", mercader, y su mujer Guiomar López, vecinos de Soria, que tenían su vivienda en el Arrabal de esta ciudad. Aunque no puede afirmarse con absoluta certeza, da la impresión de que en 1492 pasaron a Portugal junto con el padre de Guiomar, quien murió judío.

El 11 de enero de 1502 Juan de Salzedo declaró ante el Tribunal de la Inquisición, y dijo

«quel año segundo que bolvieron los judíos de Portugal, que vio este testigo a la muger de Juan Garçía, el Rico, christiano nuevo, que bive en el Arraval de Soria, que platicando con este testigo muchas vezes le dezía cómo su padre de la dicha muger avía dicho que los judíos se avían de aver en muchas persecuçiones, pero que bienaventurado sería el que se hallase judío; el qual morió judío. E que ella asy lo creya, que bienaventurado sería el que se hallase judío" ${ }^{83}$.

De lo que no cabe ninguna duda es de que Juan García y Guiomar López se habían convertido recientemente al cristianismo, como se deduce de la declaración que el 16 de febrero de 1502 hizo Juan García ante el Tribunal de la Inquisición, en la que dijo

«que de syete años a esta parte, después que este testigo e Guiomar, su muger, se tornaran christianos, le a oydo dezir a... su muger dos o tres vezes, hablando sobre los remedios de dolençias: 'Esto dezía mi padre: Parayso aya a su ley', el qual era físico e murió judío» ${ }^{84}$.

- Juan de San Esteban, cristiano nuevo vecino de San Esteban de Gormaz, y mantero de profesión. En 1492 se marchó a Portugal con su mujer; allí se convirtieron al cristianismo y retornaron a Castilla. Una vez

\footnotetext{
82 C. Carrete, op. cit, n. ${ }^{\circ} 254$, p. 114, y n. ${ }^{\circ} 434$, p. 178.

C. CARRETE, op. cit., n. ${ }^{\circ} 347$, p. 142.

C. Carrete, op. cit., n. ${ }^{\circ} 278$, p. 123.
} 
que regresó, fue nuevamente enviado a Portugal por Pero Núñez de Santa Fe, cristiano nuevo vecino de Coruña del Conde, a fin de que trajera a su mujer e hijos. El 17 de enero de 1502 Francisco del Águila, cristiano nuevo vecino de San Esteban de Gormaz, declaró ante el Tribunal de la Inquisición y dio cuenta de una conversación que había tenido con Juan de San Esteban una vez que éste había retornado de Portugal con los hijos de Pero Núñez de Santa Fe; preguntándole que cómo les iba a los judíos en Portugal,

"respondió que dellos pasavan allende, segund avía oydo dezir, e dellos se tornavan a Castilla; e que los que allá estavan fazyan muchas oraçiones e reclamos a Dios, viendo la perdizión de sus criaturas e de sus personas. E que dezyan que no podyan ser, syno que viendo sus reclamos que Dios avía de fazer algund miraglo con ellos ${ }^{85}$; e quél non quisiera venirse de allá fasta ver qué miraglo fazya Dios con ellos, e se toviera a lo ver, salvo por la priesa que le daban los fijos de Pero Núñez que se veniesen» ${ }^{86}$.

Procesado más tarde por la Inquisición, en enero de 1502 permanecía preso en las cárceles inquisitoriales.

- Juan de Salzedo, cristiano nuevo vecino de Soria. Llamado de judío rabí Yantó, en los años ochenta del siglo xv tenía a su cargo la carnicería de la aljama judía en el castillo de Soria ${ }^{87}$.

Según testimonio de Suero, vecino de Llanes (Asturias) y residente en Soria, carpintero de profesión, trabajando un día, en el año 1501, en casa de Juan de Salzedo, al abrir un hueco en una pared para meter una viga, descubrió un agujero cerrado con barro, dentro del que había unas escrituras hebreas en pergamino, consistentes en pasajes de la Torah ${ }^{88}$.

El 15 de enero de 1502 declaró Juan de Salzedo ante el Tribunal de la Inquisición y

"dixo que dos años después que se tornó christiano, o dentro de los dos años que vino de Portugal quando se tornó christiano, que en Soria, en el canpo de Santa Clara, hizieron la remembrança de la Pasyón de Ihesu Christo, a donde pasaron muchas cosas en la remembrança” 89 .

\footnotetext{
85 Es una clara manifestación del sentimiento mesiánico que se extendió entre los judíos exiliados y entre los judeoconversos españoles durante varios decenios.

86 C. CarRete, op. cit., n. ${ }^{\circ} 351$, p. 144.

C. Carrete, op. cit., n. ${ }^{\circ} 277$, p. 122 , y n. ${ }^{\circ} 354$, pp. $145-146$.

C. Carrete, op. cit., n. ${ }^{\circ} 268$, p. 119.

C. Carrete, op. cit., n. 350 , pp. 143-144.
} 
Notas acerca de la expulsión de los judios en la diócesis de Osma (Soria)

Por estas fechas contaba con unos 57 ó 58 años de edad, y permanecía preso en las cárceles inquisitoriales acusado de judaizar ${ }^{90}$. Era padre de Inés, de quien se dice que había enviudado dos veces en dos años ${ }^{91}$.

- Pero Núñez de Santa Fe, «el Ronquillo», cristiano nuevo vecino de Coruña del Conde. Se trata de uno de los personajes más importantes de la comunidad judía, y más tarde judeoconversa, de Coruña del Conde.

Llamado de judío don Yuça de Valladolid, se dedicaba asiduamente al préstamo con interés, y son varias las personas que declaran ante el Tribunal de la Inquisición haberle oído decir que no habría vuelto de Portugal si no fuera por las deudas que se le debían ${ }^{92}$; asimismo es acusado por don Bernardino Suárez de Mendoza, conde de Coruña, de ser «hombre muy logrero" y de echar a perder a muchos vecinos de lugares de su señorío con sus contratos usurarios ${ }^{93}$. Es posible que se dedicara también a la actividad mercantil, ya que en una ocasión ejemplificó haciendo referencia a sus tratos mercantiles: el 30 de diciembre de 1501 Andrés Gil, vecino de Coruña del Conde, declaró ante el Tribunal de la Inquisición y

«dixo que puede aver çinco años... que este testigo estava un día en casa de Pero Núñez, christiano nuevo, veçino de la dicha villa, e puso a este testigo una conparaçión diziéndole que quando yva a la feria e traya buena mercadería que todo el mundo ge la alabava y quél non la avía fecho buena; que quando hera judío todo el mundo le llamava don Yuça, e agora que le llaman Pero Enbudo" ${ }^{94}$.

En 1492 la familia judía de los Valladolid se dispuso a partir hacia el exilio. Su marcha hacia Portugal se hizo con toda la familia amplia reunida, y fue encabezada por las mujeres y niños, en tanto que los varones permanecieron durante algún tiempo más en su localidad de origen, sin duda con la intención de dejar solucionados diversos asuntos relacionados con sus bienes y cartas de deuda; al parecer, Pero Núñez vendió o traspasó la mayor parte de los contratos de deuda en los que figuraba como acreedor a Alonso del Castillo, pesquisidor de los bienes de los judíos en el obispado de Osma, por cuantía de ciento cuarenta mil maravedíes ${ }^{95}$. Cuando

\footnotetext{
C. Carrete, op. cit., n. ${ }^{\circ} 368$, pp. 151-153.

C. Carrete, op. cit., n. ${ }^{\circ} 125$, p. 125.

C. Carrete, op. cit., n. ${ }^{\circ} 231$, p. $107 ;$ n. ${ }^{\circ} 305$, pp. $129-130 ;$ n. ${ }^{\circ} 306$, p. $130 ;$ n. ${ }^{\circ} 308$, pp. $130-$

AGS, RGS, fol. 384; documento de 16 de diciembre de 1494.

C. CARrete, op. cit., n. ${ }^{\circ} 189$, p. 92.

AGS, RGS, fol. 384; documento de 16 de diciembre de 1494
} 
ya las mujeres y los niños habían pasado a Portugal, Pero Núñez de Santa Fe y su hermano Alonso Núñez ${ }^{96}$ decidieron convertirse al cristianismo lo que, según decían, no pudieron hacer hasta la ciudad de Zamora, donde recibieron el bautismo ${ }^{97}$. Siendo ya cristianos, pasaron a Portugal a buscar a sus mujeres e hijos,

«e con ayuda de Dios, nuestro Señor, los convertió, e resçivieron agua de Espíritu Santo».

Vueltos a Coruña del Conde, se quejaron ante la justicia regia de que, en su ausencia, les habían sido tomadas diversas propiedades que tenían en esta villa y en sus términos, así como de que algunas personas no les querían hacer efectivas las cartas de deuda que tenían contratadas de manera lícita, no pudiendo alcanzar cumplimiento de justicia por ser personas favorecidas en la villa; se cita entre estas personas a Miguel García, a Fernando León y a Pedro García Gumiel, de quienes se dice que eran alcaldes y alguaciles de Coruña del Conde ${ }^{98}$.

Acusado de judaizar, Pero Núñez de Santa Fe fue procesado por la Inquisición y condenado a cárcel perpetua y a la confiscación de sus bienes ${ }^{99}$. También fue procesada su mujer Constanza Núñez, quien en abril de 1502 permanecía en la cárcel de la Inquisición ${ }^{100}$.

5. Las consecuencias de la expulsión se dejaron sentir en diversas localidades de la diócesis de Osma, en particular en aquéllas en las que los judíos constituían un importante sector en el conjunto de la población. Éste es el caso de la villa soriana de Ágreda, de forma que el día 14 de marzo de 1493 los reyes, a petición de la universidad de la villa de Ágreda, ordenaban a las autoridades concejiles que, en adelante, el salario del corregidor no fuera de doscientos maravedíes diarios (setenta y tres mil maravedíes anuales) sino de ciento cincuenta, por cuanto

«ante que se fuesen los judios de la dicha villa avía çient vezinos, los quales pagavan su parte, e que los moros no pagavan sino quatroçientos maravedies, e se cargava todo a la dicha villa y tierra, de manera que según

96 Alonso Núñez había tenido a su cargo la carnicería judía de Coruña del Conde (C. CARRETE, op. cit., n. ${ }^{\circ} 345$, pp. 140-141), y en alguna ocasión había arrendado las rentas de las alcabalas de Arandilla, localidad burgalesa muy próxima a Coruña del Conde (C. CARRETE, op. cit., n. ${ }^{\circ}$ 202, p. 97).

97 AGS, RGS, fol. 89; documento de 9 de agosto de 1492 .

98 AGS, RGS, fol. 80; documento de 12 de septiembre de 1495.

99 C. CaRRETE, op. cit., n. ${ }^{\circ} 130$, p. 69 , y n. ${ }^{\circ} 316$, p. 133.

100 C. Carrete, op. cit., n. ${ }^{\circ} 155$, pp. 80-81. 
Notas acerca de la expulsión de los judios en la diócesis de Osma (Soria)

los pocos christianos que la dicha villa tenía, e los grandes gastos, non lo podrían conplir e se avrían de cobrar por repartimiento» 101.

Los últimos años del siglo xV y los primeros decenios del XVI estuvieron marcados por una fuerte tensión entre cristianos viejos y cristianos nuevos que, además de en las relaciones cotidianas, tuvo también su manifestación en otros acontecimientos de mayor trascendencia. Es, por ejemplo, el que tuvo por escenario la villa de Coruña del Conde, probablemente a fines del año 1493 o en 1494, consistente en la quema pública de libros hebreos; pese a que no existe constancia documental de que acciones similares fueran llevadas a cabo en otras localidades de la comarca ${ }^{102}$, es posible que no se tratara de un hecho aislado ${ }^{103}$. Este acontecimiento lo narra brevemente Antonio Triguero, vecino de la localidad burgalesa de Villanueva de Gumiel, en su declaración del día 4 de enero de 1502 ante el Tribunal de la Inquisición:

"Antonio Triguero, veçino de Villanueva de Gumiel de Yçán... dixo que luego como vinieron los christianos nuevos de Portogal, este testigo estava en la villa de Coruña e vio un día cómo en la dicha villa quemavan en la plaça las Torás e otras escripturas de judíos...» ${ }^{104}$.

La iniciativa de esta acción correspondió, a buen seguro, a la Inquisición, en un intento por erradicar cualquier resto de judaísmo entre la población judeoconversa, y pudo coincidir con el inicio o el fin de un período de gracia en la localidad. Es fácil imaginar el impacto que este acontecimiento tendría entre los judeoconversos, reflejado de manera muy expresiva en la frase pronunciada por Martín García, cristiano nuevo vecino de Coruña del Conde, quien a la vista de la quema habría dicho lapidariamente:

«O, quánta buena Ley se quema oy! ${ }^{105}$.

En definitiva, pese a la mayoritaria marcha en 1492 de los judíos que residian en distintas localidades del obispado de Osma, no fueron pocos los

101 AGS, RGS, fol. 169; documento de 14 de marzo de 1493.

102 C. CarReTe, op. cit., n. ${ }^{\circ} 200$, nota 3, p. 96.

103 Aunque para el reino de Aragón, es interesante consultar los estudios de José CABEZUDO Astrain, «La expulsión en Ejea de los Caballeros», en Sefarad, XXX (1970), p. 352, y Miguel Ángel Motıs Dolader, La expulsión de los judios de Zaragoza. Zaragoza. Diputación General de Aragón, 1985, pp. 148-149, en los que se analiza el proceso de incautación por parte de la Inquisición de los libros sagrados de los judíos, tras su expulsión del reino.

104 C. Carrete, op. cit., n. ${ }^{\circ} 200$, p. 96.

105 C, Carrete, op. cit., n. ${ }^{\circ} 200$, p. 96. 
que se convirtieron al cristianismo con ocasión de la promulgación del decreto de expulsión, así como los que regresaron algún tiempo después desde el exilio tras haber recibido el bautismo. De este modo, unidos a los no desdeñables grupos de cristianos nuevos que residian en estas mismas localidades desde fines del siglo xIV y comienzos del xv, contribuyeron a conferir peso específico a la comunidad judeoconversa en diversas localidades sorianas y burgalesas a lo largo de toda la primera mitad del siglo XVI ${ }^{106}$.

106 Una buena aproximación a este tema puede encontrarse en los trabajos de Francisco Cantera Burgos, «Conversos y judaizantes en la provincia de Soria», en Homenaje a Vicente Garcia de Diego. Revista de Dialectologia y Tradiciones Populares, XXXII (1976), pp. 87-102; Carlos Carrete Parrondo, Fontes ludaeorum Regni Castellae. II. El Tribunal de la Inquisición en el Obispado de Soria (1486-1502), Salamanca, 1985; y José María Monsalvo AnTón, «Herejía conversa y contestación religiosa a fines de la Edad Media. Las denuncias a la Inquisición en el Obispado de Osma», en Studia Historica, II/2 (1984), pp. 109-138. 